\title{
Representar territórios e des-figurar conflitos ambientais: o discurso do desenvolvimento sustentável na publicidade brasileira
}

\section{Representing territories and disfiguring environmental conflicts: the discourse of sustainable development in the Brazilian advertising}

Wendell Ficher Teixeira Assis - Doutorando em Planejamento Urbano e Regional pelo Instituto de Pesquisa e Planejamento Urbano e Regional (IPPUR) da Universidade Federal do Rio de Janeiro (UFRJ), mestre em Sociologia pela Universidade Federal de Minas Gerais (UFMG) e pesquisador do Laboratório Estado, Trabalho, Território e Natureza (ETTERN) do IPPUR. E-mail:wficher@ufrj.br.

Andréa Zhouri- Professora do Departamento de Sociologia e Antropologia da Universidade Federal de Minas Gerais (UFMG). Coordenadora do Grupo de Estudos em Temáticas Ambientais (GESTA) da UFMG. E-mail: azhouri@fafich.ufmg.br

\section{Resumo}

Com base na concepção da publicidade como instância que auxilia na composição de imaginários sociais, tentar-se-á evidenciar de que forma o discurso de empresas que utilizam o meio ambiente como suporte de suas atividades, de um lado, constrói uma legitimação de seu modo operativo e, de outro, invisibiliza a existência de populações afetadas e territórios apropriados. A ideia aqui defendida ambiciona realçar que a apropriação econômica dos territórios é consubstanciada em significações simbólicas que hierarquizam os olhares sobre a natureza, ao mesmo tempo que legitimam uma exploração calcada na iniquidade da distribuição do espaço geográfico. Procurar-se-á demonstrar, por meio da análise de anúncios dos setores químico-petroquímico e elétrico, veiculados nas revistas Veja e Exame de 1982 a 2002, como a visão econômica dominante dentro e fora do campo ambiental utiliza-se dessas significações para legitimar a continuidade da exploração capitalista dos territórios.

\section{Palavras-chave}

Conflitos ambientais. Desenvolvimento sustentável. Meio ambiente e publicidade.

\begin{abstract}
From a perspective that sees advertising as a body that assists in the composition of social imaginary, If will try to show how the discourse of companies that use the environment to support their work, builds on the one hand, a legitimacy of its operating mode, and on the other, erasing the existence of local communities and appropriate territories. The idea contained herein aims to enhance that the economic ownership of the territories is substantiated by symbolic meanings that prioritize the views of nature, while holding a sidewalk that legitimize inequality in the distribution of geographical space. Search will demonstrate through the analysis of advertisements in the chemical, petrochemical and electric, running in magazines Veja and Exame between the years 1982 and 2002 , as the dominant economic view in and out of the environmental field is used to legitimize the continuity of capitalist exploitation of the territories.
\end{abstract}

\section{Keywords}

Environmental conflicts. Sustainable development. Environment and advertising. 


\section{REINVENÇÕES DO AMBIENTE: APROPRIAÇÃO ECONÔMICA, INSTITUCIONALIZAÇÃO E LUTAS SIMBÓLICAS ${ }^{1}$}

A chamada questão ambiental tem constituído o foco das preocupações de órgãos governamentais, corporações empresariais, movimentos sociais, bem como se erigido em ferramenta de justificação de políticas públicas em âmbito nacional e internacional. A institucionalização dessa temática foi alvo, nas últimas décadas, de intensa discussão, complementada pela ocorrência de conferências no âmbito da Organização das Nações Unidas. Não obstante, o percurso de constituição dessa arena, iniciado no plano das instituições com a Conferência de Estocolmo em $1972^{2}$, assiste-se, a partir do início dos anos 90 do século XX, à consolidação da ideia hegemônica segundo a qual é possível conciliar preocupação ambiental com exploração capitalista da natureza. Assim, a noção vaga de desenvolvimento sustentável, associada a outras definições em disputa no campo ambiental (CARNEIRO, 2003; ZHOURI; LASCHEFSKI; PAIVA, 2005), tem sido utilizada por segmentos empresariais para justificar a exploração dos recursos naturais territorializados. Ao se empreender uma análise com base no conceito de campo ${ }^{3}$, intenta-se avaliar a denominada questão ambiental simultaneamente como um campo de forças e um campo de lutas. Nesse cenário, cada agente em disputa assume disposições adquiridas em lutas anteriores nas estratégias condizentes com sua posição, visando transformar ou manter os conceitos e regras vigentes. Entretanto, faz-se necessário considerar que o campo é constituído por relações objetivas que não se reduzem às interações, nem tampouco podem ser subsumidas no conjunto de estratégias individuais (BOURDIEU, 1990). O que está em disputa no campo são definições e categorizações que devem ser legitimadas e consagradas no âmbito social.

\footnotetext{
Este artigo é uma versão ampliada de ASSIS, Wendell Ficher Teixeira. In-visibilizar Populações e Legitimar Iniquidades: A apropriação do discurso do desenvolvimento sustetável na publicidade do setor elétrico, que foi publicada em ZHOURI, A. (Org.). As Tensões do Lugar: Hidréletricas, Sujeitos e Licenciamento Ambiental, Belo Horioznte: Ed. UFMG, 2011. p. 219-238.

2 A Conferência das Nações Unidas sobre o Meio Ambiente Humano, realizada em Estocolmo no período de 5 a 16 de junho de 1972, reuniu representantes de vários países, dos mais ricos aos mais pobres, visando avaliar as necessidades de desenvolvimento em concomitante respeito à natureza. A reunião marcou o início de uma série de outras conferências realizadas pela Organização das Nações Unidas para debater temas específicos levantados durante o encontro, tais como alimentação, moradia e população. O mote principal dessa conferência era a necessidade de estabelecer critérios e princípios que oferecessem a todos os povos uma inspiração para a preservação do meio ambiente.

3 O conceito de campo aqui empregado tem origem em Bourdieu (1989) e define-se como o lócus em que se trava uma luta concorrencial entre agentes em torno de interesses específicos. O que está em jogo nessa luta é o monopólio da autoridade definida, de maneira inseparável, como capacidade técnica e poder social; ou, se quisermos, o monopólio da competência compreendida enquanto capacidade de falar e agir legitimamente, isto é, de maneira autorizada e com autoridade.
} 
Na perspectiva aqui adotada, a lógica de apropriação da natureza é mais bem entendida quando relacionada à ideia de campo ambiental, no qual se manifestam lutas para a imposição de noções simbólicas e materiais relacionadas ao meio ambiente. Do mesmo modo que o que está em disputa no campo da arte é a legitimidade dos produtores artísticos (BOURDIEU, 1989), no campo ambiental, os seus agentes (ambientalistas, corporações empresariais, órgãos gestores, movimentos sociais) digladiam-se para impor uma definição do que seja sustentabilidade, impacto ambiental, reassentamento, população atingida, área protegida, desmatamento, poluição, entre outras questões ${ }^{4}$. A construção de uma análise baseada no conceito de campo permite compreender os posicionamentos assumidos por cada um dos atores sociais envolvidos, relacionando-os aos lugares que ocupam no interior da mesma estrutura. A partir dessa abordagem, percebe-se que o habitus ${ }^{5}$ de cada sujeito integrante do campo ambiental ajusta-se à apropriação econômica da natureza, ao mesmo tempo que possibilita compreender os arranjos que lhe são ofertados e as tomadas de decisão daí resultantes. Nota-se, assim, que os objetivos em relação ao meio ambiente estão vinculados ao modo de vida de cada ator ou segmento, constituindo-se numa manifestação social e cultural que lança um olhar específico sobre a realidade material (LEMOS, 1999) ${ }^{6}$.

A problemática em torno da qual se organiza o conceito de campo ambiental pode ser, portanto, caracterizada como um processo de produção econômica e de reprodução social que encara a natureza como um bem a ser apropriado e utilizado. A natureza é, assim, significada a partir de relações culturais que agem na atribuição de sentidos e delineiam os graus variados de sua relevância. É nesse cenário, no qual se enfrentam posições sociais divergentes, que a natureza surge como sujeita às atribuições de significado de cada integrante do campo. Adentra-se em um terreno no qual o conflito ambiental ocorre por meio da mescla de interesses sociais e de significados culturais, que são orientados pela forma como a natureza é vista, significada e explorada. Não se trata, pois, de abolir um degrade calcado

4 Apesar de ser recente a existência de um campo ambiental, muitas das visões que hoje estão em disputa em seu interior podem ser consideradas como tributárias tanto da compreensão iluminista de uma natureza controlada pela razão, quanto da idealização de uma natureza pristina e intocada (CARVALHO, 2001) ou, ao extremo, como oriundas do raciocínio de desfrute incondicional e predatório, presente durante as bandeiras colonizadoras.

5 Bourdieu (1989) define habitus como um sistema de disposições inconscientes que resultam da interiorização das estruturas objetivas que, de um lado, produz uma determinação do futuro objetivo e das esperanças subjetivas e, de outro, orienta práticas sociais que, por sua vez, são objetivamente ajustadas às estruturas experimentadas.

6 Aqui é importante salientar que a apropriação material da natureza que chamamos de produção decorre de sua apropriação simbólica - "a produção então, é a prática de uma lógica muito mais penetrante do concreto, lógica que é produzida como uma apropriação simbólica da natureza" (SAHLINS, 1979, p. 217). 
na racionalidade econômica; trata-se, antes, de fundar uma nova racionalidade que implique uma forma de pensar mais holística, bem como contemple modos distintos de apropriação dos recursos territorializados.

É nesse cenário, no qual se enfrentam posições sociais divergentes, que a natureza se apresenta como sujeita às atribuições de significado de cada integrante do campo. Assim sendo, a apropriação social da natureza não se esgota em um sistema prático de exploração econômica; ao contrário, corresponde a um conjunto de ideias que enriquecem aos interesses encapados no interior do campo ambiental e lhes dão sentido. Dessa maneira, os mecanismos de apropriação da natureza podem ser considerados como tributários de uma ordem simbólica que atribui significado à exploração e legitima o desenvolvimento das forças produtivas como essenciais à manutenção da vida humana. Em relação a esse aspecto, é de fundamental importância que decifremos como a noção de desenvolvimento sustentável tem servido de alicerce à manutenção de um modo de produção altamente degradante.

Para O'Connor (2002), desenrola-se uma luta em escala mundial para definir o conceito de sustentabilidade. Segundo o autor, há quatro sentidos principais para o vocábulo: 1) sustentar o curso da acumulação capitalista; 2) proporcionar meios de vida aos povos do mundo; 3) sustentar o modelo capitalista sem comprometer as formas de vida que têm sido subvertidas por relações salariais e mercantis; 4) assegurar a sustentabilidade ecológica. Alinhavando cada um desses sentidos, a noção de desenvolvimento sustentável tem sido utilizada por vastos segmentos sociais para justificar as mais diversas atividades empresarias. Considerando-se que, "quanto mais significados admitem, mais poderosos se tornam os símbolos" (SACHS, 2002, p. 1), pode-se dizer que essa assimilação de diretrizes multiformes tem conferido eficácia à utilização da ideia de desenvolvimento sustentável ${ }^{8}$. Ancorado em uma estratégia que crê no gerenciamento racionalizado da natureza, no qual a eficiência técnica é o leitmotiv do crescimento econômico, o desenvolvimento sustentável pertence à categoria das palavras mágicas e necessárias ao incremento das forças produtivas.

Tradução do original em espanhol, de nossa autoria.

8 Ao percorrermos a trajetória de consolidação da ideia de desenvolvimento sustentável, verificamos que sua introdução é resultante de um longo processo que se inicia durante a Conferência de Estocolmo em 1972. Embora o conceito de ecodesenvolvimento utilizado no início dos anos 80 já contenha o cerne de uma possível conjugação da exploração econômica com a preservação ambiental, é somente a partir da elaboração do Relatório Nosso Futuro Comum, conhecido como Relatório Brundtland (COMISSÃO MUNDIAL SOBRE MEIO AMBIENTE E DESENVOLVIMENTO, 1991), que a noção de sustentabilidade surge como estratégia política de desenvolvimento. A partir desse ponto, a noção de desenvolvimento sustentável é gestada como uma alternativa para transpor o abismo existente entre exploração capitalista de recursos naturais e preservação ambiental. 
Pode-se dizer que a ideia de desenvolvimento sustentável é elaborada em uma perspectiva que visa revigorar os pilares de sustentação do progresso econômico. Ademais, se em uma perspectiva social, o desenvolvimento econômico capitalista acarreta um conflito entre crescimento e distribuição, na perspectiva ambiental, aparece como uma contradição entre conservação e exploração (LEFF, 1994). Para O'Connor (2002), em muitos casos, as lutas ambientais e pela criação de esferas reguladoras têm forçado os capitais a internalizarem custos, que de outro modo recairiam por completo sobre o meio ambiente. A esse respeito, constatam-se divergências entre dois tipos de racionalidade: uma que tende a maximizar as condições de reprodução social e outra que visa a maximizar os benefícios comerciais provenientes do intercâmbio de mercadorias (LEFF, 1994). Dito de outra forma, embora os recursos naturais sejam a base do modo de produção capitalista, sua incorporação ao sistema de geração de lucros é totalmente descaracterizada. Ao serem caracterizados como externalidades, os impactos ambientais são vistos como resultantes de inadequações da natureza, antes que um reflexo da incapacidade do mercado (ACSERALD, 2001).

A noção hegemônica de desenvolvimento sustentável é gestada como uma alternativa para transpor o abismo existente entre exploração capitalista de recursos naturais e preservação ambiental ${ }^{9}$. A noção de desenvolvimento sustentável é elaborada em uma perspectiva que visa revigorar os pilares de sustentação do progresso econômico e está calcada numa sobredeterminação da esfera econômica incapaz de reconhecer o fato de que "a economia é, ao mesmo tempo, a ciência mais avançada matematicamente e a mais atrasada humanamente" (MORIN, 1981, p. 16). Ao se ater à primazia da racionalidade econômica capitalista, o desenvolvimento sustentável desconsidera a existência de conflitos de poder em torno da noção de sustentabilidade e obscurece a influência de outras importantes esferas. Alicerçando-se em uma ótica econômica cujos pilares são a mitigação, a compensação, a conciliação e a harmonia, a noção de desenvolvimento sustentável tem sido incapaz de contabilizar valores incomensuráveis, tais como equidade social, diversidade cultural, autonomia e autogestão. Nesse contexto, a proteção ambiental é considerada como um custo para o processo econômico, que, em suma, é formulado com base na ideia de sustentabilidade tributária dos princípios de

9 A COMISSÃO MUNDIAL SOBRE MEIO AMBIENTE E DESENVOLVIMENTO (CMMAD) da Organização das Nações Unidas (ONU) estabelece os principais objetivos a serem almejados pelo desenvolvimento sustentável, dentre os quais se destacam: retomar o crescimento, alterar a qualidade do desenvolvimento, atender às necessidades essenciais de emprego, alimentação, energia, água e saneamento, manter um nível populacional sustentável, conservar e melhorar a base de recursos, reorientar a tecnologia e administrar o risco e incluir o meio ambiente e a economia no processo de tomada de decisões (COMISSÃO MUNDIAL SOBRE MEIO AMBIENTE E DESENVOLVIMENTO, 1991, p. 53). 
uma racionalidade mecanicista e de curto prazo (LEFF, 2002). O destaque maior é dado à refuncionalização da economia, que descaracteriza a incongruência entre o paradigma da sustentabilidade social e o da exploração econômica, aglutinando ambos no projeto de subsumir a natureza na esfera econômica.

A racionalidade econômica pode até, com certas limitações, internalizar os princípios da sustentabilidade ecológica. Não obstante, um compromisso latente com os ganhos de capital impede-a de incorporar referenciais da justiça ambiental, que frequentemente têm sido relegados a objetivos de segunda ou terceira ordem. Pode-se dizer que as forças dominantes no campo ambiental têm moldado um discurso hegemônico de sustentabilidade sintonizado com os princípios de iniquidade na distribuição e de aproveitamento dos recursos territorializados. Como se tentará demonstrar, o discurso publicitário dos setores elétrico e químicopetroquímico apropria-se dessa ideia hegemônica de desenvolvimento sustentável para formular uma visão unívoca de natureza que tende a dar continuidade à exploração capitalista do meio ambiente. Ademais, obscurece significados tradicionais e invisibiliza outras visões sobre o território ${ }^{10}$, ao mesmo tempo que estabelece uma recodificação do espaço como lugar da geração de riquezas. Até aqui foram expostas as vantagens de uma abordagem calcada no conceito de campo e a institucionalização da ideia de desenvolvimento sustentável; passar-se-á agora à exposição das estratégias que orientarão a análise dos anúncios publicitários.

\section{PLATAFORMAS E MARCOS PARA A COMPREENSÃO DO DISCURSO PUBLICITÁRIO}

Analisar a produção material com base em uma matriz de pensamento mais complexa (MORIN, 1999) requer contrastá-la com um olhar que revela os aspectos culturais e as diferentes ordens que a compõem. Essa diretriz permite, por exemplo, conjecturar que a construção que se processa no canteiro de obras para a implantação de uma hidrelétrica não é em grande medida diferente daquela operada pelo discurso publicitário empenhado em erigir fortes estruturas simbólicas para a legitimação da obra. Assim sendo, a análise dos anúncios objetiva perscrutar os artifícios utilizados na tarefa de construir uma significação simbólica acerca da exploração ambiental, demonstrando que "cabe a um dos sujeitos - o polo emissor - escolher o termo mais marcado que, de certa forma, assegurará algum

10 As disputas para que certas representações do território tornem-se hegemônicas entrelaçam-se com os conflitos prático-reais no que tange às atribuições e aos usos dos recursos naturais. $\mathrm{O}$ território extrapola, portanto, uma definição físico-geográfica e alcança a dimensão das relações de poder subjacente a cada uma das formas de apropriação do espaço (RAFFESTIN, 1993). 
tipo de elo associativo com o imaginário do outro - o pólo receptor" (CASTRO, 2001). Nesse sentido, o discurso publicitário, embora fictício, é uma reconstituição de cenas da vida cotidiana ou social, cuja fonte é um acervo cultural compartilhado, pois têm o dever de ser parte interessada na expressão de representações. Com base nessa abordagem, verifica-se que os conteúdos apresentados ao imaginário social $^{11}$, por intermédio da publicidade, são significações do espaço social e reflexos de posições hegemônicas dentro e fora do campo ambiental.

Deter-se na análise de textos e imagens publicitárias é antes uma tarefa que requer investigar as vozes e os olhares que orientam a produção dos anúncios. Assim, pode-se compreender a publicidade como receptáculo dos discursos que circulam no interior do campo ambiental e como reflexo do estilo impresso pelas empresas anunciantes. Como evidencia Orlandi (1988), o uso do discurso constitui um ato social com todas as suas implicações, conflitos, reconhecimentos, relações de poder e constituição de identidades, de modo que a seleção que o sujeito faz entre o que diz e o que não diz é extremamente significativa. Avalia-se que a estratégia utilizada pelos anunciantes que recorrem à publicidade busca, de um lado, harmonizar os impactos ambientais e, de outro, consolidar uma imagem corporativa de respeito à natureza e às comunidades ${ }^{12}$. Segundo Gracioso (1995), existem cinco grandes temas que são alvos de campanhas institucionais ${ }^{13}$ : 1) valorização do consumidor; 2) respeito à natureza - preocupação com proteção e preservação ambiental; 3) empresa cidadã - integração na comunidade; 4) ética nos negócios; 5) empresa parceira - estímulo à participação de empregados. A utilização de temas como os que denotam respeito à natureza e integração à comunidade pode ser encarada, de um lado, como resposta à crescente importância da esfera ambiental e, de outro, como indício da pressão exercida pelos movimentos sociais organizados ${ }^{14}$. Nesse sentido, à medida que a sociedade institui padrões

11 Quando nos referimos ao conceito de imaginário social, temos em mente as formulações de Baczko (1985), que o concebe como uma peça efetiva e eficaz do dispositivo de controle da vida coletiva e em especial do exercício da autoridade e do poder. Destarte, podemos considerar o discurso publicitário como uma das esferas que intervêm na consolidação e no exercício desse poder.

12 Matéria da revista Veja, de 17 de setembro de 1991, intitulada "Os executivos verdes", destaca as duas faces do papel desempenhado por publicitários: "em seu ramo pérfido faz apenas uma maquiagem ecológica em produtos e empresas que desejam mostrar-se simpáticos às causas ambientais, já no ramo honesto ajuda a influir nos processos de produção e no conteúdo dos produtos, objetivando harmonizar empresa e meio ambiente".

13 As campanhas institucionais objetivam reforçar ou mudar a imagem pública de uma empresa. Não têm o objetivo imediato de promover a venda; antes, procuram aceitação e predisposição a uma ideia do anunciante.

14 Matéria de capa da revista Exame, de 10 de julho de 1991, apresenta um receituário para lidar com as questões ambientais e com as pressões decorrentes desses assuntos. Descreve, portanto, um quadro a ser implementado por empresas que atuam nesses segmentos: 1) Sempre que 
valorativos e critérios de sucesso, e forma os temores e esperanças humanos, ela como que engendra o material do qual a propaganda extrai a sua força vital (BARAN; SWEEZY, 1978, p. 210).

A publicidade pode ser encarada como parte integrante das mercadorias visuais, ao mesmo tempo que resultado e consequência de uma rede de valores econômicos, culturais, simbólicos e políticos (CANEVACCI, 2001). Admite-se, portanto, a importância da publicidade como instrumento heurístico que auxilia na compreensão dos imaginários sociais (RIAL, 1999) e sugere-se:

Além do papel regulador que pretende desempenhar nas economias de mercado, a publicidade é reconhecida hoje em dia, unanimemente, como um processo de produção plena de formas culturais e se afirma no espaço social como um dos suportes mais visíveis das representações de identidade (SOULAGES, 1996, p. 142).

A visão que orienta a análise dos anúncios procura, portanto, desvendar a junção entre o texto publicitário e a imagem a ele conectada, buscando fazer ressurgir as formas culturais que são sugeridas ao imaginário social. Nesse jogo, a imagem pode funcionar como um eficiente texto; e este, como um decodificador que clarifica aspectos não explícitos na imagem. É a conexão dessas duas esferas, operada dentro de um campo simbólico de representação, que organiza e dissemina uma noção de meio ambiente, preservação, conservação e exploração sintonizada com as marcas e posições assumidas pelos anunciantes ${ }^{15}$. Assim sendo, é fecundo realçar algumas dimensões na análise das peças publicitárias, por exemplo, quando e em que situação ocorre a publicação de um anúncio; quais os modos de apreensão e o comportamento sugeridos; quais os objetos ou situações utilizados e de que maneira são representados; como é reunido um material diverso para comunicar novos valores e, por último, quais fatores estão ausentes do discurso. Uma importante sutileza da imagem publicitária consiste numa inversão em relação ao mundo: em lugar de ir da cena ao sentido (a qualidade do evento preexiste à visão), vai do sentido à cena (coloca as relações que motivam a visão). Desse

tomar uma decisão, qualquer que seja, leve em conta a ecologia. Jamais a deixe em segundo plano; 2) Mantenha um diálogo constante com grupos ecologistas; 3) Incentive a formação de um grupo de ambientalistas entre os funcionários. Eles poderão defender causas impossíveis, mas certamente darão boas sugestões; 4) Coloque na diretoria alguém incumbido das questões ambientais e 5) Faça tudo isso convencido de que é o caminho certo e não porque alguém o força a fazê-lo.

15 O que se ressalta aqui está em sintonia com os conceitos bourdianos de campo e de habitus que foram pormenorizados na seção anterior. Considera-se que as representações dos agentes variam de acordo com sua posição (e os interesses a ela associados), segundo seu habitus como sistemas de apreciação e percepção, bem como em decorrência das estruturas cognitivas e avaliatórias adquiridas por meio das experiências e visões de mundo (BOURDIEU, 1990). 
modo, constrói e delineia as imagens em harmonia com os atributos e ideias que pretende apresentar ao mundo social.

Ao analisar as imagens por esse prisma, percebe-se que elas podem ofertar sentidos e sugerir novas acepções acerca da realidade social. Entretanto, não se trata de desvendar uma realidade que se esconde atrás de um texto ou de uma imagem, nem de trazer à tona os elementos de manipulação que o texto eventualmente esconde, mas de tentar interpretar o que o texto pretende construir (BRAGA, 2000). Assim, realçar o lugar sociológico do produtor/emissor, bem como suas visões de mundo e o espaço que ocupa na produção simbólica, torna-se necessário, se o intento é compreender os significados que um anúncio pretende construir e ofertar aos receptores. Essa problemática é reforçada quando se constata que "as palavras mudam de sentido segundo as posições daqueles que as empregam e tiram seu sentido dessas posições, isto é, em relação às formações ideológicas nas quais essas posições se inscrevem" (ORLANDI, 1988, p. 58). Para Maingueneau (2002), um texto publicitário não pode ser estudado exclusivamente como um tipo de estrutura textual, uma sequência coerente de signos verbais, nem como um dos elementos das estratégias de marketing. Ao contrário, deve ser visto como uma atividade enunciativa ligada a um gênero de discurso: o lugar social do qual emerge, o canal por onde passa (oral, escrito, visual), bem como o tipo de difusão que implica não são dissociáveis do modo como o texto se organiza. Nesse sentido, pode-se afirmar sobre a confecção desse discurso:

Não são apenas as palavras e as construções, o estilo e o tom que significam. Há aí um espaço social que significa. O lugar social do falante e do ouvinte, o lugar social da produção do texto, a forma de distribuição do texto e o valor da revista como parte e mecanismo da industrial cultural, tudo isso significa (ORLANDI, 1996, p. 55).

A compreensão de um anúncio se dá a partir do deciframento de características que não estão, necessariamente, presentes nos dispositivos linguísticos ou imagéticos que o compõem. Para Foucault (1972), a tarefa da análise de discursos consiste, não mais em destrinchar o conjunto de signos (de elementos significantes que remetem a conteúdos ou representações), mas em concebê-los como práticas que formam, sistematicamente, os objetos a que se referem. Ao se considerar essa dimensão, nota-se que o discurso publicitário, deliberadamente, constrói um novo sentido para os objetos e situações que representa. Assim sendo, a utilização por parte do discurso publicitário de noções em disputa no campo ambiental - como equilíbrio homem/natureza, essencialidade da produção, conciliação entre exploração e preservação, respeito às gerações futuras, sustentabilidade, entre outras - reflete uma forma especifica 
de significar a natureza, ao mesmo tempo que auxilia na constituição de novas verdades descredenciadoras de outros sentidos possíveis. Abre-se espaço para a compreensão dos anúncios a partir do conceito de silenciamento (ORLANDI, 1995), que se fundamenta no pressuposto de que, como o sentido é sempre produzido a partir de uma posição do sujeito, ao dizer, ele estará necessariamente não dizendo outros sentidos possíveis, mas indesejáveis, em uma dada situação discursiva. Estabelece-se um recorte entre o que é dito e o que não se deve dizer, entretanto, esse não dito já é por si só carregado de significações que merecem ser elucidadas. Ademais, esse silenciamento não deixa de significar uma postura que, por um lado, desqualifica os valores de ribeirinhos, camponeses e populações tradicionais e, por outro, reafirma as disparidades presentes na condução dos processos de licenciamento ambiental ${ }^{16}$.

O discurso publicitário dos segmentos químico, petroquímico e elétrico contempla uma forma específica de apresentar e conceber a natureza, de modo que compreender o processo de construção da realidade, partindo da produção de sentidos instituídos pela esfera midiática, exige articular o conjunto de interesses em disputa no terreno social, bem como entrever as significações que são mais adequadas ao fato em questão (CASTRO, 1997). Por outro lado, é factível considerar que o discurso publicitário distribuído por esses setores industriais acaba por substituir a realidade vivenciada e estabelece-se com mais força simbólica que a própria experiência fenomenológica ${ }^{17}$. Com o intuito de clarificar a apropriação

16 O licenciamento ambiental é concebido em três fases: licença prévia, licença de instalação e licença de operação. A participação formal das populações atingidas apenas acontece após a realização dos estudos de viabilidade ambiental apreciados durante a fase de licenciamento prévio. A interferência nas decisões limita-se, portanto, à participação em uma audiência pública que visa a apresentar os estudos à população. Não obstante, a possibilidade de influir na condução do processo é extremamente restrita, visto que os moldes de constituição do licenciamento avaliam a realização dos empreendimentos como inexorável. Para uma abordagem mais detalhada, ver contribuições de Zhouri, Laschefski e Paiva (2005).

17 Indicativos desse processo são evidenciados em Castro (1997), que, ao descrever a luta salarial dos trabalhadores da construção civil em Belo Horizonte no ano de 1979, aponta a existência de uma nova significação produzida pela mídia local e nacional. Nesse cenário, desaparece o sentido de reivindicação salarial ofuscado pelos órgãos de imprensa, e apresenta-se uma nova significação, na qual a greve é transformada em um evento de baderna. Outro traço desse processo pode ser percebido no relato de uma representante do corpo técnico da Fundação Estadual do Meio Ambiente (FEAM), durante reunião do Conselho de Política Ambiental (COPAM). Ao comentar a exibição de campanhas publicitárias da Usina de Irapé, construída no vale do Jequitinhonha, expôs conversa tida com uma moradora ribeirinha, da localidade de Barra do Salinas, situada a jusante da Usina de Irapé e ameaçada pela construção de outro empreendimento. A propósito de uma propaganda televisiva que mostrava atingidos por Irapé em novas e espaçosas casas, a moradora comentou que gostaria de ser atingida, porque assim mudaria para uma casa muito melhor. Com base nesse relato, pode-se constatar que, ao atualizar os fatos por um prisma específico, a publicidade acaba por apresentar um discurso que invisibiliza o real, ao mesmo tempo que apresenta uma visão maquiada e distorcida dos 
que o discurso publicitário realiza da ideia de desenvolvimento sustentável, bem como de noções em disputa no campo ambiental, analisar-se-á na próxima seção alguns anúncios veiculados nas revistas Veja e Exame, de 1982 a 2002 ${ }^{18}$. Entretanto, isso não será realizado para fazer ressurgir os anúncios; ao contrário, intenta-se recompô-los a partir de um olhar que observa e reconhece caracteres à primeira vista não percebidos.

\section{INVISIBILIZAR POPULAÇÕES E DESFIGURAR CONFLITOS AMBIENTAIS}

A análise dos anúncios do setor elétrico permite subdividir o intervalo 1982-2002 em três fases interpenetráveis: 1) 1982-1987, fase que antecede a formulação dos preceitos do desenvolvimento sustentável; 2) 1987-1997, fase que marca a absorção da ideia de compatibilidade entre exploração capitalista e preservação ambiental; 3) 1997-2002, fase que consolida uma visão hegemônica de desenvolvimento sustentável e desconstrói a imagem de uma natureza modificada. As representações do setor elétrico veiculadas durante o intervalo 1982-1987 desconsideram a existência de impactos sociais ou ambientais. Todavia, notase nesses anúncios a introdução de um discurso que atribui usos e significados primordiais à natureza e a concebe como geradora de riqueza e de engrandecimento da nação. Indicativos desse tipo de abordagem são explicitados em um anúncio da Companhia Hidroelétrica do São Francisco, que ressalta as vantagens da construção

eventos. De fato, parece existir algo mais. Não se trata apenas de uma ressignificação, mas da produção e da atribuição de novos significados aos eventos.

18 Em relação à escolha do recorte temporal, escolheu-se um intervalo de vinte anos, compreendidos entre 1982 e 2002. O marco inicial corresponde a um ponto temporalmente equidistante entre duas das principais conferências sobre meio ambiente e desenvolvimento, situando-se, portanto, a dez anos da Conferência de Estocolmo (1972) e a dez da Conferência do Rio de Janeiro (1992). Dessa maneira, considera-se ser possível tanto captar os traços prevalecentes em Estocolmo, que ecoaram na produção de anúncios dos anos 80 , quanto mapear as escolhas e atitudes que antecederam a realização de uma nova conferência. Por outro lado, pode-se, a partir desse recorte, evidenciar as estratégias que influenciaram duas décadas, uma que antecede a realização da Rio Eco 92 e outra que marca os desdobramentos experimentados nos anos 2000. Acatou-se como referência temporal a realização de grandes conferências, por se avaliar que esses eventos são catalisadores de novas atitudes, bem como esferas de estabelecimento de diretrizes normativas ou consultivas para o meio ambiente. Durante a pesquisa, foram analisadas 1.448 revistas, compreendendo 953 números de Veja e 495 de Exame. Ao fim, encontramos 461 anúncios; desse total, 102 eram repetidos (73 em Veja e 29 em Exame), restando-nos 359 para análise. Todavia, em virtude das limitações deste artigo, debruçar-nos-emos aqui sobre os anúncios considerados paradigmáticos. 
da Usina de Sobradinho" 19 . A manchete principal do anúncio apregoa "Sobradinho, novos horizontes para o sertanejo", ao que se segue o seguinte texto:

O Rio São Francisco tem sido, desde os primeiros passos da nossa história, a razão de viver de milhares de brasileiros, habitantes de suas margens. Utilizando suas vazantes para o cultivo de alimentos, capturando peixes em suas lagoas, cavalgando seu dorso macio a bordo das gaiolas [...]. Mas esse rio de cartão postal sobreviveu até a década de 40. A criação da Chesf - Companhia Hidroelétrica do São Francisco - lançou as bases para a nova civilização da energia elétrica: a da industrialização. Um tempo de grandes transformações nas vidas das pessoas e até do rio. [...] A fome de energia de origem hídrica impunha algo muito maior.

Da análise desse fragmento, infere-se que o discurso publicitário ressignifica o rio como espaço da industrialização e da fome de energia hídrica, ao mesmo tempo que introduz uma racionalidade econômica capaz de atribuir novos significados aos espaços naturais e descaracterizar os usos tradicionais outrora praticados. O rio cartão-postal, de vazantes, pescarias e dorso macio, é simbólica e objetivamente transformado nas bases de uma civilização industrial. Ademais, impõe-se um desenvolvimento unidimensional, representado como possibilidade de novos horizontes para o povo sertanejo. É possível indicar que durante essa fase não há a preocupação discursiva em compatibilizar natureza e produção econômica; ao contrário disso, o meio ambiente é racionalizado como o lugar único e exclusivo da geração de riquezas. Por outro lado, há indicativos daquela visão, destacada por Pádua (2002), que reconhece a pujança das riquezas naturais, mas considera a destruição um preço a pagar pelo progresso. Diferentemente dessa fase, o período que compreende o intervalo entre os anos 1987 e 1997 é marcado pela introdução de novas referências no discurso que promove a implantação de usinas hidrelétricas. Embora permaneçam as balizas que reafirmam a necessidade de construção de novos empreendimentos, geração de empregos, ampliação do parque energético, crescimento econômico, desenvolvimento nacional, progresso e outras tantas benesses, o discurso passa a incorporar os traços resultantes da institucionalização do campo ambiental, da introdução da ideia de desenvolvimento sustentável e da irrupção de movimentos sociais organizados ${ }^{20}$.

19 Anúncio publicado na revista Veja, edição 721, de 30 de junho de 1982, página 112.

20 A organização de movimentos sociais de resistência à construção de barragens intensifica-se a partir do final da década de 80. Embora as lutas tenham se iniciado por volta de 1978, quando da construção da Usina de Itaipu, a disseminação de projetos hidrelétricos nas regiões Norte e Nordeste, associada às experiências negativas das populações já deslocadas, provoca pressões por melhores negociações e condições de reassentamento. Em relação a isso, são emblemáticas as lutas empreendidas por populações atingidas pelas hidrelétricas de Itapararica, no Nordeste, e de Machadinho, no Sul do Brasil. Todavia, mesmo expressando uma identidade aglutinadora de repúdio à instalação de hidrelétricas, esses movimentos possuíam traços particulares e não articulavam preocupações de âmbito nacional. A organização de um movimento nacional 
Constata-se, ainda que de forma ligeira, a veiculação de anúncios nos quais as imagens de usinas são apresentadas dividindo espaço e conectadas com outras figuras ilustrativas, tais como plantações irrigadas, animais resgatados, casas construídas, populações reassentadas. O padrão de representação começa a alterar-se, espelhando a assimilação dos preceitos difundidos com base na noção hegemônica de desenvolvimento sustentável. Quanto a isso, o anúncio de inauguração da Usina Hidrelétrica de Itaparica representa um exemplo bastante ilustrativo e traz as seguintes imagens dispostas em quadros de diversos tamanhos que preenchem os $2 / 3$ superiores da página: 1 ) diversas casas que são apresentadas a partir de um ângulo aéreo, 2) campos plantados e irrigados, 3) patos nadando em um lago, 4) imagens em close de casas aparentemente novas, 5) uma cobra enrolada nos braços de uma pessoa e 6) a imagem de uma usina captada do alto, ocupando uma porção maior e em um campo privilegiado de visão.

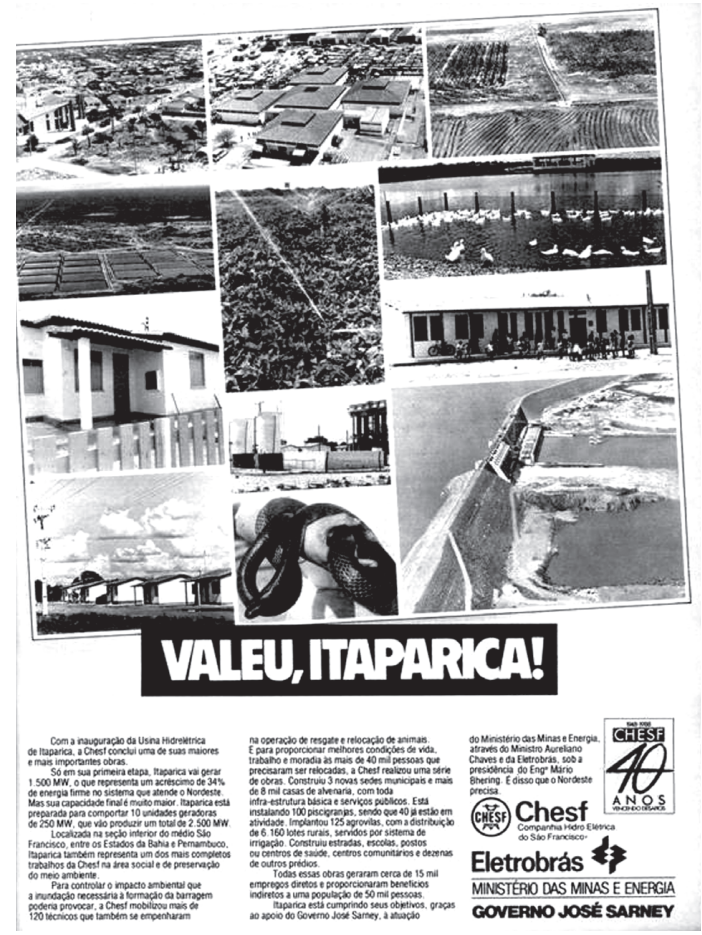

Figura 1. Anúncio publicado na revista Veja (ano 20, n. 37, 14 set. 1988, p. 117).

ocorre somente a partir da realização do I Encontro Nacional de Trabalhadores Rurais Atingidos por Barragens, realizado em Goiânia, em abril de 1989. Durante esse encontro, são lançadas as bases para a constituição do Movimento de Atingidos por Barragens (MAB), que se firma durante o I Congresso Nacional de Atingidos por Barragens, ocorrido em março de 1992. Desde os anos 90, o MAB tem fortificado a resistência à realização de hidrelétricas, ao mesmo tempo que confronta as necessidades políticas e organizacionais do movimento nacional e regional (VAINER, 2004). 
A análise desse conjunto possibilita confirmar que a imagem da usina ligada às ilustrações de casas construídas, plantações irrigadas e animais resgatados traduz, ainda que de forma incipiente, a ideia de compatibilidade entre exploração econômica capitalista, preservação ambiental e respeito às comunidades. A manchete do anúncio coroa essa possibilidade com a frase "Valeu, Itaparica!", que é complementada pelo seguinte texto iniciado na parte de baixo da página: "Localizada na seção inferior do médio São Francisco, entre os estados da Bahia e Pernambuco, Itaparica também representa um dos mais completos trabalhos da Chesf na área social e de preservação do meio ambiente”. As estratégias utilizadas permitem verificar que o discurso publicitário começa a incorporar o uso de caracteres simbólicos que anteriormente estavam ausentes nas representações do setor elétrico. Nesse contexto, as noções de controle de impactos ambientais e de reconhecimento de populações atingidas começam a ter visibilidade. Indicativos dessa estratégia discursiva podem ser extraídos do seguinte trecho: "Para controlar o impacto ambiental que a inundação necessária à formação da barragem poderia provocar, a Chesf mobilizou mais de 120 técnicos que também se empenharam na operação de resgate e realocação de animais". Com base nesse fragmento, constatase que inexiste um raciocínio calcado na mitigação ou na compensação de impactos. Ao contrário, está em vigor um controle técnico que tende a evitar os problemas que ocorreriam com a inobservância desse preceito. $\mathrm{O}$ aprimoramento técnico aparece como descredenciador da ocorrência de impactos sociais e ambientais, ao mesmo tempo que reafirma as possibilidades de controle sobre a natureza.

Com relação aos impactos sociais e às populações atingidas, outro extrato desse anúncio é bastante significativo: "E para proporcionar melhores condições de vida, trabalho e moradia às mais de 40 mil pessoas que precisaram ser realocadas, a Chesf realizou uma série de obras". Embora esse anúncio seja o primeiro a incorporar a existência de populações atingidas, verifica-se que o discurso de assimilação é forjado com base na concepção segundo a qual as hidrelétricas são provedoras de melhores condições de vida à população deslocada. Os impactos sobre o modo de vida das populações atingidas são minimizados, e a medida sugerida restringe-se à realização de obras de engenharia. A análise dos anúncios veiculados nessa segunda fase possibilita demonstrar que a construção de hidrelétricas permanece sendo representada com base na positividade e na essencialidade da produção de energia elétrica. De todo modo, há uma incorporação ainda incipiente do discurso do desenvolvimento sustentável; contudo, reafirmase a tendência anterior, subsistindo uma significação na qual a usina aparece, de um lado, como promotora de progresso e crescimento econômico e, de outro, como obscurecedora da ocorrência de impactos sociais e ambientais negativos. 
Nesse sentido, o discurso publicitário reforça a positividade das usinas, agregando uma quimérica preocupação ambiental que tende a descaracterizar a existência de impactos e a extrair vantagens competitivas dessa incorporação.

No percurso dessa trilha, o intervalo entre 1997 e 2002 representa a consolidação plena da ideia de desenvolvimento sustentável na publicidade do setor elétrico. Enquanto o discurso dos períodos anteriores ignora a existência de impactos ou descaracteriza sua ocorrência, essa nova etapa apresenta um reconhecimento das modificações e estabelece os mecanismos técnicos capazes de sanar os problemas ocasionados. A partir dessa nova fase, a descaracterização dos conflitos cede espaço à incorporação de estratégias calcadas nas possibilidades de compensação e de mitigação dos impactos socioambientais. Isso pode ser evidenciado em um anúncio da Usina de Canabrava, que traz em destaque a imagem de uma hidrelétrica ocupando toda a porção superior da página e tendo logo abaixo, em diagramação menor, os seguintes quadros: 1) outra imagem da usina em funcionamento, 2) um filhote de mico amparado nas mãos e sendo amamentado com uma seringa, 3) plantações irrigadas e 4) uma senhora e um senhor sorridentes e uma casa ao fundo. A utilização dessas imagens representa a incorporação de uma visão hegemônica no campo ambiental, aquela que apregoa a possibilidade de equilíbrio entre exploração econômica capitalista, preservação ambiental e respeito às comunidades. Percebe-se uma anexação por parte da publicidade de imperativos presentes no receituário do desenvolvimento sustentável e vislumbrase uma reorientação no discurso que promove a implantação de usinas.

Sabendo-se que a imagem publicitária confere sequencialidade e direcionalidade ao olhar, é possível captar um percurso que parte da imagem da hidrelétrica (em destaque), passa pela inclusão da natureza, contempla a possibilidade de melhores cultivos e alcança a inclusão e a satisfação das populações atingidas. É possível afirmar, sobre esse aspecto, que o discurso utilizado se alimenta de concepções em disputa no campo ambiental e procura reconciliar as incongruências existentes entre exploração econômica, preservação ambiental e interesses comunitários. Essa estratégia discursiva é evidenciada no trecho disposto na parte inferior da página: "Em tudo que a Tractebel faz existe uma filosofia de somar benefícios para multiplicar soluções. [...] Somando energia e responsabilidade social, ela gera infinitas soluções para o país e a comunidade local". O discurso publicitário reafirma as possibilidades de conciliação e introduz em seu léxico o uso de medidas compensatórias ou mitigadoras (consagradas pela visão hegemônica no campo), que procuram invisibilizar os impactos sociais e ambientais por meio do uso de aparatos técnicos. Evidenciam-se indícios dessas formulações no seguinte fragmento: 


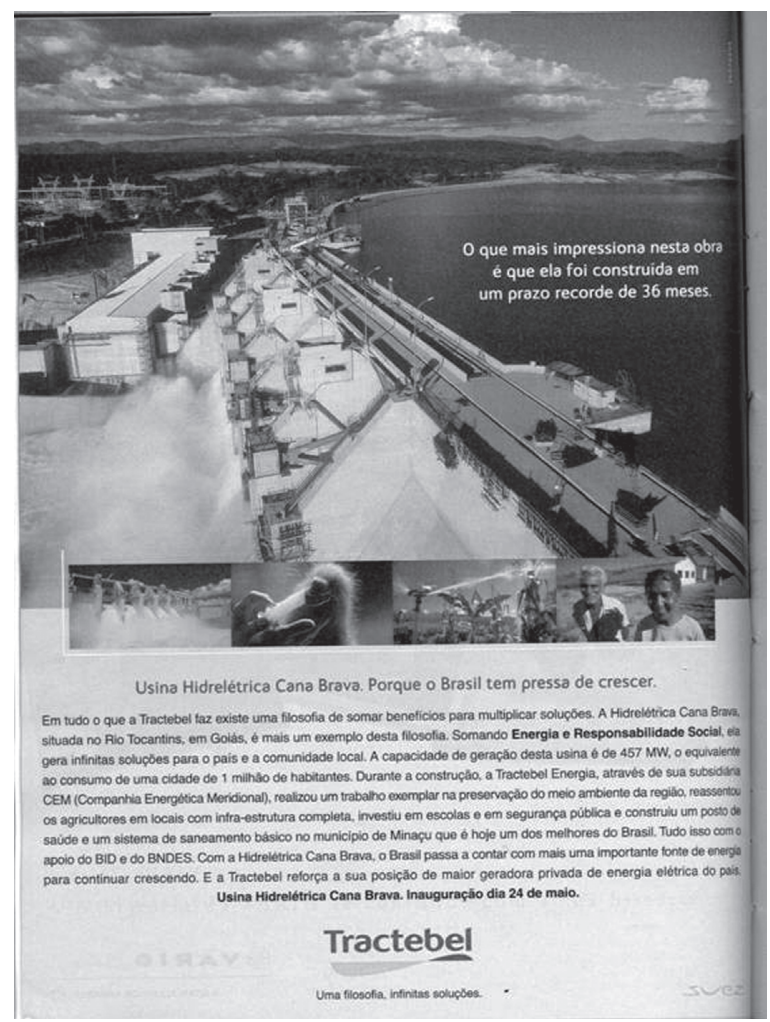

Figura 2. Anúncio publicado na revista Veja (n. 1752, 22 maio 2002, p. 52).

Durante a construção, a Tractebel Energia [...] realizou um trabalho exemplar na preservação do meio ambiente da região, reassentou os agricultores em locais com infraestrutura completa, investiu em escola e segurança pública e construiu um posto de saúde e um sistema de saneamento básico no município de Minaçu, que é hoje um dos melhores do Brasil.

Nesse trecho, o anúncio objetiva demonstrar que as relações entre desenvolvimento e meio ambiente não são inexoravelmente excludentes. Assim, promove-se uma apropriação discursiva de valores e noções fortemente destacados no campo ambiental, para construir uma imagem-ilusão de que a construção de usinas não representa um comportamento predatório. Por outro lado, esse discurso ressignifica as medidas compensatórias, apresentando-as como vantagens que advêm da implantação dos empreendimentos, ao mesmo tempo que invisibiliza os impactos sobre as populações afetadas. Por outro lado, o anúncio propala as vantagens dos empreendimentos realizados sem a presença econômica do Estado, revigorando as bases do novo marco regulatório do setor elétrico que sancionou a possibilidade de investimentos exclusivos da iniciativa privada. Para marcar uma 
distinção em relação à morosidade associada à figura do Estado, o anúncio afirma nas duas manchetes a eficiência e a rapidez dos negócios privados: a primeira, no alto e no centro da página, logo acima da imagem do lago, propala: "o que mais impressiona nessa obra é que ela foi construída no prazo recorde de 36 meses"; a segunda, no meio da página, entre as imagens, complementa esses sentidos, ao proclamar: "Usina de Canabrava, porque o Brasil tem pressa de crescer".

A análise dos anúncios veiculados no intervalo dessas duas décadas permite constatar uma reorientação do discurso que promove a operação do setor elétrico. O conjunto de estratégias empregado na primeira fase, quando vigorava uma significação da natureza como locus da geração de riquezas, paulatinamente incorpora atributos da noção hegemônica de desenvolvimento sustentável. Ademais, uma observância retórica dos impactos ambientais e sociais trilha esse mesmo caminho, passando por dois estágios: o primeiro, da descaracterização e da minimização; o segundo, da mitigação e da compensação. De todo modo, percebe-se que essa assimilação discursiva intenta manter um modelo continuado de exploração da natureza, ao mesmo tempo que justifica a realização dos empreendimentos no contexto da luta dos movimentos sociais por respeito às comunidades e ao meio ambiente.

O tipo de estratégia empregado na publicidade do setor elétrico, bem como a divisão em três períodos, pode também ser divisado nos anúncios das indústrias químicas e petroquímicas. Todavia, em virtude de uma percepção mais imediata dos impactos ambientais, sobretudo da poluição atmosférica e da contaminação de rios e solos, há uma reação discursiva mais precoce nesses segmentos ${ }^{21}$. Assim sendo, pode-se indicar que a ausência de tratamento dos efluentes, a contaminação dos cursos de água, a produção de lixo tóxico, além do registro de altos índices de poluição atmosférica, contribuíram para que a opinião pública formulasse uma imagem negativa dos setores químico e petroquímico, vinculando-os à destruição e à degradação do meio ambiente. Isso gerou uma reação discursiva que nega a ocorrência de impactos ambientais e procura desvincular a indústria

21 A associação entre poluição e indústria química/petroquímica era imediata durante os anos 80. Exemplo disso é o fato de a cidade de Cubatão (SP), onde existia um grande número de empresas desse setor, ter sido considerada nessa época como a capital mundial da poluição. A revista Exame de julho de 1991 traz um histórico dos grandes acidentes ocorridos: 1) em 1984, um vazamento de 700.000 litros de gasolina de dutos da Petrobras matou noventa pessoas e feriu outros duzentos moradores da vila de Socó, em Cubatão; 2) em 1985, uma nuvem de gás amônia provocou a evacuação da favela Vila Paris; 3) um estudo da Universidade de São Paulo constatou que entre os anos 1982 e 1985 quase 9.000 crianças nasceram sem cérebro em Cubatão, vítimas dos altos índices de poluição atmosférica. 
química e petroquímica dos danos causados à natureza. Esses aspectos podem ser evidenciados em um anúncio da Oxiteno $\mathrm{S} / \mathrm{A}^{22}$ que descarta o uso de imagens e apresenta o seguinte texto em letras grandes e preenchendo toda a página: "Por que será que a grande maioria das pessoas acredita que toda mulher bonita é burra, todo espanhol é briguento, todo corintiano é sofredor, todo pescador é mentiroso e que toda violência contra o meio ambiente é causada pela indústria petroquímica?" Ao apropriar-se de características presentes em nosso imaginário social, esse anúncio suscita o questionamento e a reflexão sobre a validade desses postulados, ao mesmo tempo que reage contra o argumento que vincula a atuação da petroquímica à violência contra a natureza. Dessa forma, a preservação da natureza é incorporada ao discurso publicitário como negativa da relação de causa e efeito entre indústria química/petroquímica e impactos socioambientais. Além disso, pode-se captar nesse anúncio a aceitação, subliminar, de que as atividades desses setores ocasionam impactos ambientais, porém não são isoladamente responsáveis por toda a violência contra a natureza. Sem embargo, o caráter essencial desse segmento continua sendo tonificado no slogan disposto ao pé da página: "O maior risco não é viver com a química. É viver sem ela".

A estratégia discursiva que nega a ocorrência de impactos socioambientais é paulatinamente substituída por um discurso que reafirma noções hegemônicas de desenvolvimento sustentável vigentes no campo ambiental. Isso pode ser percebido em um anúncio da Companhia Petroquímica do Sul, que, disposto em duas páginas, apresenta à esquerda a imagem de um filhote de pássaro no ninho. No alto da página e significando aspectos não explícitos na imagem, visualizamos a manchete: "A Copesul comunica o nascimento de uma nova espécie de empresa”.

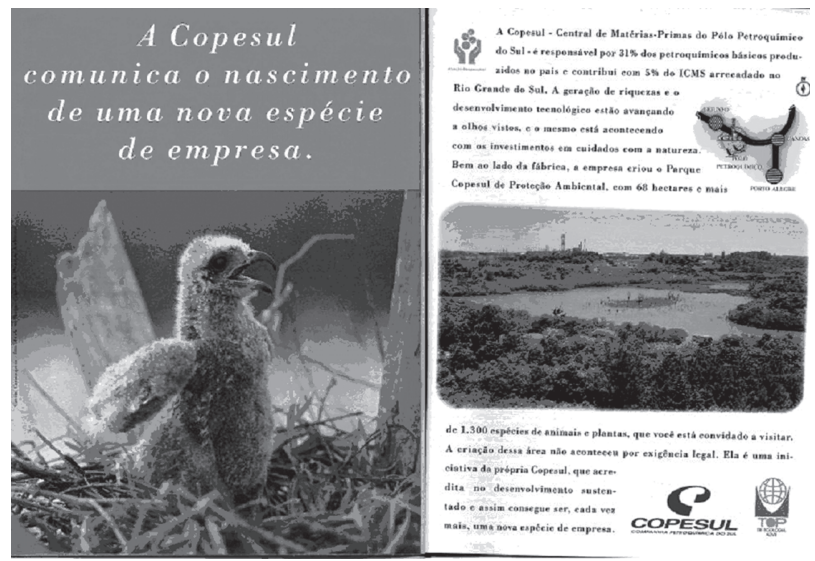

Figura 3. Anúncio publicado na revista Exame (n. 547, 22 dez. 1993, p. 92).

22 Publicado na revista Veja (ano 20, n. 12, 23 mar. 1988, p. 12). 
O texto iniciado na página da direita reitera e complementa os sentidos expressos por esse conjunto e esclarece que essa nova espécie de empresa é constituída por corporações que integram suas atividades ao meio ambiente. Percebe-se o uso de um discurso que valoriza a natureza como esfera importante na condução das atividades da indústria petroquímica. Não obstante, essas formulações são construídas com base em denominações que refletem visões dominantes no campo ambiental e reafirmam a conciliação e o aprimoramento técnico como instrumentos capazes de sanar os problemas ocasionados. Nesse sentido, o texto diagramado na página da direita apresenta o volume de produção e a geração de impostos, para em seguida relacioná-los com os dispêndios em proteção ambiental: “A geração de riquezas e o desenvolvimento tecnológico estão avançando a olhos vistos e o mesmo está acontecendo com os investimentos em cuidados com a natureza". Esse fragmento mostra uma integração discursiva da natureza, o que, todavia, deve-se a uma contrapartida em investimentos financeiros, e não à absorção de uma mentalidade que questione os modos de produção utilizados pela companhia.

O uso de paisagens naturais é reforçado na página da direita, que apresenta a imagem de uma lagoa cercada por vegetações preservadas e tendo ao fundo a chaminé de uma fábrica. Essa imagem traduz uma visão que se apropria do meio ambiente, apresentando-o em consonância com os interesses da atividade produtiva. A figura do pássaro no ninho representando o nascimento de uma nova espécie de empresa, bem como a da lagoa e da vegetação em equilíbrio com a fábrica, constituem indicativos desse tipo de abordagem.

Analisando-se esse anúncio, constata-se que, diferentemente do setor elétrico, a indústria química/petroquímica pauta-se, desde o início da década de 90, por definições consagradas pela ideia hegemônica de desenvolvimento sustentável. Ao congregar as noções de mitigação de impactos, respeito às gerações futuras, equilíbrio entre produção e preservação, adequação técnica da produção e outras mais, o discurso publicitário passa a ocultar os impactos socioambientais gerados por essas indústrias. A possibilidade de convivência harmônica com a natureza invisibiliza e recobre as modificações ocorridas na paisagem e nas relações sociais, bem como justifica a manutenção e a continuidade das atividades do setor químico-petroquímico. De todo modo, o discurso publicitário dos três segmentos examinados reforça a racionalidade tecnocientífica como saída para evitar impactos e como manutenção do modelo de produção capitalista.

Os anúncios veiculados pelo setor químico-petroquímico no intervalo de duas décadas permitem constatar a existência de uma transição discursiva. Da essencialidade dos produtos como justificativa para os possíveis impactos, passa-se à assimilação 
da noção de desenvolvimento sustentável e à pressuposta harmonia entre natureza, comunidades e produção. Ao contrário do setor elétrico, no qual a importância atribuída à temática ambiental é mais tardia, no discurso da indústria petroquímica, isso ocorre, mesmo que de forma enfraquecida, ainda na primeira fase de 1982 a 1987. Além disso, a absorção da ideia de desenvolvimento sustentável e a utilização de noções hegemônicas no campo ambiental já caracterizam o discurso da petroquímica desde o início dos anos 90, enquanto no setor elétrico isso somente ocorrerá no princípio da década seguinte. Conjectura-se que a visibilidade e a percepção dos impactos ocasionados pela indústria química e petroquímica, associadas à adequação às novas exigências de mercado, demandaram uma reação mais breve.

\section{CONCLUSÃO}

A construção de um imaginário social acerca da atuação dos setores elétrico e químico-petroquímico atrela-se à economia de mercado e reafirma as possibilidades de um controle técnico da natureza, transmitindo uma ideologia que propala a existência de um progresso erigido sobre bases ambientalizadas. $\mathrm{O}$ processo de institucionalização da temática ambiental representa a consolidação dos imperativos (outrora defendidos pelos intelectuais racionalistas) da eficiência como gestora do modelo de exploração. Verifica-se que o discurso publicitário dos três segmentos pesquisados apregoa a permanência de um desfrute dos recursos naturais, contudo, isso passa a ser mediado por uma visão que incorpora retoricamente a importância de certa concepção de natureza, bem como apresenta os mecanismos capazes de manter a exploração do espaço natural. Nesse contexto, constrói-se um ambiente passível de modificações e desconsidera-se a existência de outros usos e atribuições sobre os territórios. Da mesma forma, arquiteta-se uma ideia de desenvolvimento na qual o significado de natureza é remodelado e ressignificado. Sendo assim, a publicidade representa um dos indicativos de que a questão ambiental tem logrado atingir consciências e alcançado uma importância política. Sem embargo, permanece distante dos meandros que determinam os rumos da economia e acaba incorporada unicamente como indício de uma adequação quimérica dos setores produtivos. A natureza permanece sendo o espaço da geração de riquezas, porém a doxa que impera no campo ambiental passa a realizar uma ambientalização dos empreendimentos degradadores da natureza, tornando-os compatíveis com o meio ambiente.

A partir da interpretação dos anúncios, compreende-se que a célebre frase atribuída a Maquiavel - "governar é fazer crer" - pode ser adaptada e assumir a 
forma do preservar é fazer $\mathrm{crer}^{23}$. Constata-se que o discurso publicitário formula artifícios simbólicos capazes de influir na criação de uma imagem-ilusão que vincula a exploração do meio ambiente ao comprometimento dos segmentos produtivos com a preservação da natureza. Nesse cenário, o intuito primordial dos anúncios é o de demonstrar que as relações entre progresso econômico e meio ambiente não são inexoravelmente excludentes. Para tanto, incorporam a dimensão ambiental apenas como vantagem competitiva e enfatizam uma noção de oportunidade empresarial atrelada aos pressupostos da racionalidade econômica. Promovem, então, uma apropriação discursiva de valores e conceitos fortemente destacados no campo ambiental, objetivando construir uma imagem quimérica de que as empresas abandonaram um comportamento predatório e aderiram à causa preservacionista e ambientalista.

Ao se orientar por essas formulações, o discurso publicitário obscurece a existência de custos ambientais, ao mesmo tempo que legitima uma apropriação desigual dos recursos territorializados. Além disso, possibilita a solvência da contradição existente entre desenvolvimento econômico e conservação da natureza, ao empregar um aparato discursivo que, de um lado, artificializa e tecnifica o meio ambiente e, de outro, faz circular um ideário que perpetua e legitima o ritmo de exploração. Por outro lado, torna-se evidente que essas reconciliações somente são factíveis por serem patrocinadas por um olhar hegemônico que obscurece a existência de outras esferas valorativas e de outros olhares possíveis. Os anúncios propagam visões acerca da natureza que invisibilizam os impactos sociais e ambientais, bem como obscurecem as modificações na paisagem. Assim, ao afirmar os preceitos hegemônicos no campo ambiental, o discurso publicitário opera um silenciamento dos modos de vida comprometidos pela instalação dos empreendimentos e forja sistematicamente as representações distribuídas ao imaginário social, que por sua vez auxiliam na composição dos olhares através do quais os indivíduos avaliam a implantação de uma hidrelétrica ou de um complexo petroquímico.

23 Artigo do então presidente da Du Pont (multinacional da indústria química) para o Brasil e América do Sul, publicado na revista Exame, em 21 de julho de 1993, incorpora essa tendência e apregoa: "Não importa se acreditamos que operamos com uma performance razoável, o que importa é se a opinião pública nos percebe como seguros quando o assunto é meio ambiente. O nosso desafio é incorporar a ética ambientalista. Devemos enxergar a natureza como algo maior do que somente uma fonte de suprimentos de matérias-primas ou um local de depósito de rejeitos. As indústrias devem investir na redução do impacto ambiental de suas operações e na correção dos problemas que possam existir. Ampliando a capacidade de produção sem impactar o meio ambiente e reciclando quando possível, a indústria estará aumentando suas oportunidades de mercado". Nesse trecho, constata-se que, apesar de uma tentativa de valorização da temática ambiental, mantêm-se os arraigados pressupostos de uma racionalidade econômica que busca uma melhor percepção na opinião pública. 


\section{REFERÊNCIAS}

ACSELRAD, H. Externalidade ambiental e sociabilidade capitalista. In: CAVALCANTI, C. (Org.). Desenvolvimento e natureza: estudos para uma sociedade sustentável. São Paulo: Cortez, 2001. p. 128-138.

BACZKO, B. Imaginário social. In: Enciclopédia Einaudi. Lisboa: Imprensa Nacional, 1985. p. 296-332.

BARAN, P.; SWEEZY, P. M. Teses sobre a propaganda. In: COHN, G. (Org.). Comunicação e indústria cultural: leituras de análises dos meios de comunicação na sociedade contemporânea e das manifestações da opinião pública, propaganda e cultura de massas nessa sociedade. São Paulo: Nacional, 1978. p. 205-214.

BAUDRILLARD, J. O sistema dos objetos. São Paulo: Perspectiva, 1968.

BOURDIEU, P. A economia das trocas simbólicas. São Paulo: Perspectiva, 1974.

O poder simbólico. Rio de Janeiro: Bertrand Brasil, 1989.

Coisas ditas. São Paulo: Brasiliense, 1990.

BRAGA, J. L. Lugar de fala como conceito metodológico no estudo de produtos culturais. In: ESTEVES, J.P. et al. Mídias e processos socioculturais. São Leopoldo: Unisinos, 2000. p. 159-184.

CANEVACCI, M. Antropologia da comunicação visual. Rio de Janeiro: DP\&A, 2001.

CARNEIRO, E. J. Modernização recuperadora e o campo da política ambiental em Minas Gerais. 2003. Tese (Doutorado em Ciências Humanas) - Faculdade de Filosofia e Ciências Humanas, Universidade Federal de Minas Gerais, Belo Horizonte, 2003.

CARVALHO, I. C. de M. A invenção ecológica: narrativas e trajetórias da educação ambiental no Brasil. Porto Alegre: UFRGS, 2001.

CASTORIADIS, C. A instituição imaginária da sociedade. Rio de Janeiro: Paz e Terra, 1982.

CASTRO, M. C. P. Na tessitura da cena, a vida: comunicação sociabilidade e política. Belo Horizonte: UFMG, 1997.

CASTRO, M. L. D. Estratégias de um texto publicitário. In: RAMOS, R. (Org.). Mídia, textos e contextos. Porto Alegre: EDIPUCRS, 2001. p. 99-110. 
COMISSÃOMUNDIALSOBREMEIO AMBIENTEEDESENVOLVIMENTO. Nosso futuro comum. Rio de Janeiro: Fundação Getúlio Vargas, 1991.

DONDIS, D. A sintaxe da linguagem visual. São Paulo: Martins Fontes, 1997. DUARTE, E. B. Sobre o texto fotográfico. In: BRITO, Y. C. F. de; OLIVEIRA, A. C. M. A. de (Orgs.). Imagens técnicas. São Paulo: Hacker, 1998.

FOUCAULT, M. A arqueologia do saber. Petrópolis: Vozes, 1972.

GRACIOSO, F. Propaganda institucional: nova arma estratégica da empresa. São Paulo: Atlas, 1995.

LEFF, E. Ecología y capital: racionalidad ambiental, democracia participativa y desarrollo sustentable. México: Siglo Veintiuno, 1994.

Saber ambiental: sustentabilidade, racionalidade, complexidade, poder. Petrópolis: Vozes, 2001.

La ecología política en América Latina: un campo en construcción. Polis, Revista de la Universidad Bolivariana, v. 2, n. 5, p. 125-145, 2003. Disponível em: <www.revistapolis.cl>. Acesso em: 23 out. 2003.

LEMOS, C. F. de. Audiência pública, participação social e conflitos ambientais nos empreendimentos hidrelétricos: os casos de Tijuco Alto e Irapé. 1999. Dissertação (Mestrado em Planejamento Urbano e Regional) Instituto de Pesquisa e Planejamento Urbano e Regional, Universidade Federal do Rio de Janeiro, Rio de Janeiro, 1999.

MAINGUENEAU, D. Novas tendências em análise do discurso. Campinas: UNICAMP, 1997.

Análise de texto de comunicação. São Paulo: Cortez, 2002.

MORIN, E. La ecología de la civilización técnica: de la noción de medio técnico al ecosistema social. Revista Teorema, Valencia, n. 46, p. 5-17, 1981.

O problema epistemológico da complexidade. Lisboa: EuropaAmérica, 1999.

O'CONNOR, J. Es posible el capitalismo sostenible? In: ALIMONDA, H. (Comp.). Ecología política. Naturaleza, sociedad y utopía. Clacso, 2002. Disponível em: <www.clacso.org>. Acesso em: 14 jun. 2004.

ORLANDI, E. P. Discurso \& leitura. Campinas: Cortez, 1988.

As formas do silêncio: no movimento dos sentidos. Campinas: Unicamp, 1995.

A linguagem e o seu funcionamento: as formas do discurso. Campinas: Pontes, 1996. 
PÁDUA, J. A. Um sopro de destruição: pensamento político e crítica ambiental no Brasil escravista, 1786-1888. Rio de Janeiro: Jorge Zahar, 2002.

PÉNINOU, G. Física e metafísica da imagem publicitária. In: METZ, C. (Org.). A análise das imagens. Petrópolis: Vozes, 1973. p. 60-81.

PENN, G. Analise semiótica de imagens paradas. In: BAUER, M. W.; GASKELL, G. (Org.). Pesquisa qualitativa com texto, imagem e som: um manual prático. Petrópolis: Vozes, 2002. p. 319-342.

RAFFESTIN, C. Por uma geografia do poder. São Paulo: Ática, 1993.

RIAL, C. S. Publicidade e etnia no Brasil. In: PINHO, J. B. Trajetória e questões contemporâneas da publicidade brasileira. São Paulo: Intercom, 1998. p. 129-145.

SACHS, W. Globalización y sustentabilidad. World Summit Papers, Johannesburg, n. 6, p. 1-38, 2002. Disponível em: <www.wupperinst.org>. Acesso em: 14 jul. 2003.

SAHLINS, M. Cultura e razão prática. Rio de Janeiro: Zahar, 1979.

SOULAGES. J-C. Discurso e mensagens publicitárias. In: CARNEIRO, A. D. (Org.). O discurso da mídia. Rio de Janeiro: Oficina do Autor, 1996. p. 142-154.

VAINER, C. B. Águas para vida, não para morte: notas para uma história do movimento de atingidos por barragens. In: ACSELRAD, H.; HERCULANO, S.; PÁDUA, J. A. (Org.). Justiça ambiental e cidadania. Rio de Janeiro: Relume Dumará, 2004. p. 185-215.

ZHOURI, A. L. M. Ambientalismo e antropologia: descentrando a categoria de movimentos sociais. Teoria e Sociedade, Belo Horizonte, v. 8, p. 10-29, 2001.

(Org.). As tensões do lugar: hidrelétricas, sujeitos e licenciamento ambiental. Belo Horizonte: UFMG, 2011.

ZHOURI, A. L. M.; LASCHEFSKI, K.; PAIVA, Â. Uma sociologia do licenciamento ambiental: o caso das hidrelétricas em Minas Gerais. In: ZHOURI, A. L. M.; LASCHEFSKI, K.; BARROS, D. P. (Org.). A insustentável leveza da política ambiental: desenvolvimento e conflitos socioambientais. Belo Horizonte: Autêntica, 2005. p. 89-116. 